\title{
Microstructure Formation Driven by Stored Energy and Mechanical Property of Pure Titanium Recycled from Chips by Severe Plastic Deformation
}

\author{
Peng Luo* \\ Shanghai Collaborative Innovation Center for Heavy Casting/Forging Manufacturing Technology, \\ School of Materials, Shanghai Dianji University, Shanghai 201306, P. R. China
}

It is of practical significance to improve the recycling value of hard-to-deform titanium wastes by means of melting-free technologies. One such technology, severe plastic deformation in the form of equal channel angular pressing (ECAP) was used to consolidate chips of commercial purity titanium. Electron backscatter diffraction (EBSD) was used to resolve the microstructure into high angle grain boundaries (HAGBs, with misorientation $\geq 15^{\circ}$ ) and low angle grain boundaries (LAGBs, $<15^{\circ}$ ). The strain energy stored in HAGBs and LAGBs were considered to be the primary driving force of dynamic recovery (DRV) and dynamic recrystallization (DRX). As a result of DRV and DRX, the formation of microstructure was analyzed by evaluating the stored energy for various ECAP conditions. The ductility of the recycled titanium was analyzed by verifying the failure mode according to the inspection of the fracture surface of the tensioned specimen with scanning electron microscopy. [doi:10.2320/matertrans.M2018322]

(Received October 2, 2018; Accepted January 25, 2019; Published March 1, 2019)

Keywords: titanium, microstructure, grain boundary, stored energy, mechanical property

\section{Introduction}

To reduce efficiently economic/environmental impact derived from industrial wastes is the prerequisite to sustainable growth. In order for the innovation of the current melting-based recycling technologies, the concept of industrial ecology via a solid-state recycling has been discussed. ${ }^{1)}$ Some easily deformed metals, e.g., copper and aluminum, are easy to be recycled by solid-state technologies. For example, a process of severe plastic deformation (SPD) termed high-pressure torsion was found to be effective to consolidate machining chips of pure copper and $\mathrm{AlSi}_{8} \mathrm{Cu}_{3}$ alloy. ${ }^{2,3)}$ These paper demonstrated that the introduction of SPD could be possibly a beneficial way for improving the recycling value of hard-to-deform titanium.

During plastic deformation, only a small proportion $(\sim 15 \%)$ of deformation work was converted to the energy that can be stored in metals, ${ }^{4}$ ) but the formation of microstructure is driven by the energy stored in it. The stored energy in cold-rolled nickel has been analyzed by transmission electron microscopy (TEM). ${ }^{5)}$ However, the representativeness of TEM was confined with a very small observing area. In contrast, electron backscatter diffraction (EBSD) has a broader scope of vision than TEM, and can resolve at a large scale, ultrafine-grains $(<1.0 \mu \mathrm{m})$ with high angle grain boundaries (HAGBs, with misorientation $\geq 15^{\circ}$ ) and low angle grain boundaries (LAGBs, <15 $\left.{ }^{\circ}\right){ }^{6-9)}$ The strain energy stored in HAGBs and LAGBs were considered to be the primary driving force of dynamic recovery (DRV) and dynamic recrystallization $(\mathrm{DRX}){ }^{10)}$ So, this paper aims to understand the effect of the stored energy on the formation of microstructure via DRV and DRX. The mechanical property of the recycled titanium was studied by verifying the failure mode according to the inspection of the fracture surfaces of tensioned specimens with scanning electron microscopy (SEM).

\section{Experimental Procedure}

With the sizes averagely being less than $1 \mathrm{~mm}$ in thickness, and several millimeters in width and length, chips of commercial purity titanium (ASTM Grade 2) were consolidated by SPD in the form of equal channel angular pressing (ECAP) using a die with two equal channels in diameter $(\Phi 11 \mathrm{~mm})$ intersecting at $90^{\circ}$. A forward plunger imposed a pressure up to $\sim 1.0 \mathrm{GPa}$ and moved at a speed about $10^{-4} \mathrm{~m} \mathrm{~s}^{-1}$. Simultaneously, a back plunger provided a back-pressure $\sim 50 \mathrm{MPa}$. A heating device stabilizing the temperature within $\pm 1 \mathrm{~K}$ was designed to heat the die to 723 or $863 \mathrm{~K}$. ECAP was conducted following route C, i.e., $180^{\circ}$ rotations clockwise about the sample's longitudinal axis (with respect to the pressing direction) between passes. ${ }^{11)}$ After ECAP, the sample was quenched with cold water to maintain the microstructure formed at high temperature. Based on the Archimedes' principle, a Mettler Toledo 33360 density determination kit was used to confirm that full density $\left(4.51 \times 10^{-3} \mathrm{~kg} \mathrm{~m}^{-3}\right)$ was readily obtained. The sample for metallographic characterization was chopped along cross and longitudinal section, respectively, then ground using $\mathrm{SiC}$ abrasive grinding papers with P-Grades up to 2500. The polishing was conducted in a solution of $\mathrm{CH}_{3} \mathrm{OH}(600 \mathrm{ml})$, $\mathrm{HClO}_{4}(60 \mathrm{ml})$ and $\mathrm{C}_{4} \mathrm{H}_{9} \mathrm{OCH}_{2} \mathrm{CH}_{2} \mathrm{OH}(360 \mathrm{ml})$ at $30 \mathrm{~V}$ for $20 \mathrm{~s}$ at $263 \mathrm{~K}$ or with a colloidal silica suspension in a VibroMet Buehler at $220 \mathrm{VAC} 50 \mathrm{~Hz}$. EBSD was conducted in a JEOL JSM 7001F FEGSEM and FEI NOVA NanoSEM 230. The results of EBSD were analyzed by a subroutine HKL Channel 5 TANGO. For mechanical property, at a strain rate of $1 \times 10^{-3} \mathrm{~s}^{-1}$, tensile testing was conducted using flat dog-bone plate samples $(10 \mathrm{~mm}$ in gauge length, and averagely $6 \times 2 \mathrm{~mm}^{2}$ in rectangular cross section) on the MTS-810 machine equipped with a standard non-contacting laser extensometer (MTS-LX500). Chemical compositions were analyzed by inductively coupled plasma atomic emission spectroscopy (ICP-AES). 


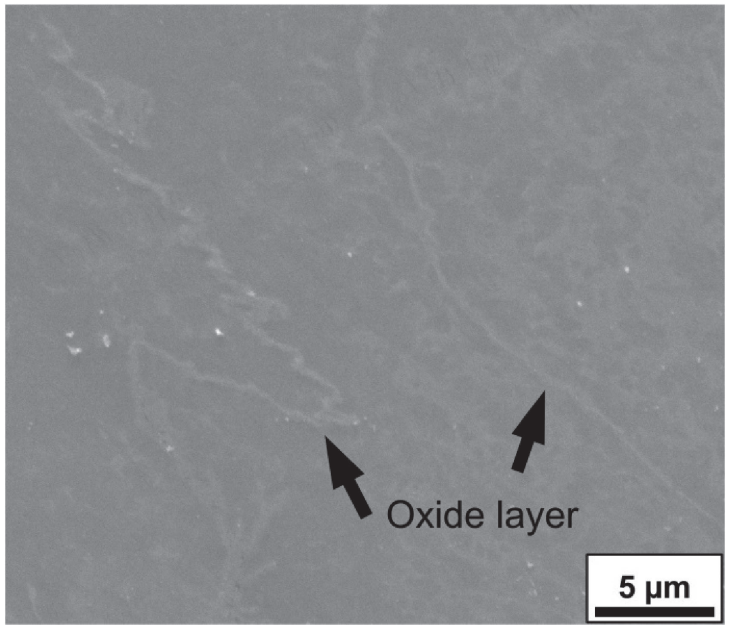

Fig. 1 SEM micrograph of commercial purity titanium recycled by ECAP at $723 \mathrm{~K}$ for 8 passes, indicating a porosity-free microstructure containing oxide layers.
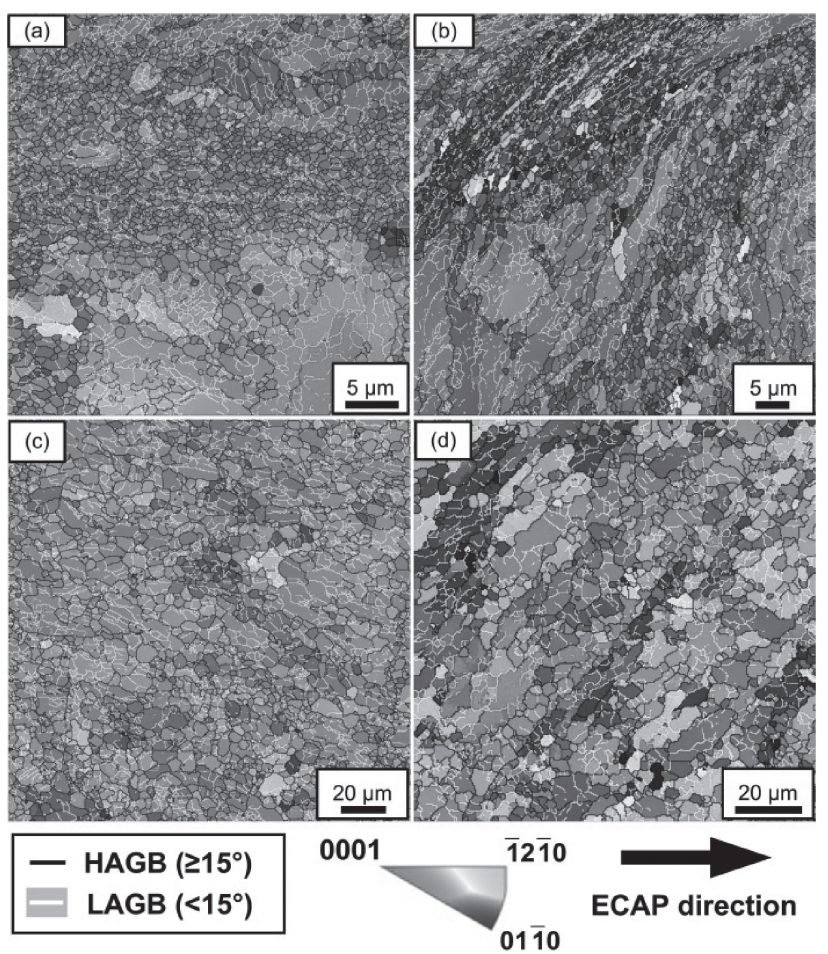

Fig. 2 Representative EBSD microstructure after 4 passes at $723 \mathrm{~K}$ on (a) cross and (b) longitudinal section; at $863 \mathrm{~K}$ on (c) cross and (d) longitudinal section, respectively.

\section{Results and Discussion}

As shown in Fig. 1, the absence of visible porosity and micro-crack was confirmed by SEM inspecting a polished surface of the sample subjected to ECAP at $723 \mathrm{~K}$ for 8 passes. The operation of the polishing followed the specification of metallography. ${ }^{12)}$ Very thin oxide layers (chip boundaries) were clearly revealed (arrowed in Fig. 1). Figure 2 shows representative microstructures resolved by EBSD for the consolidated samples. Accordingly, statistical distribution of the misorientation across HAGBs or LAGBs is shown Fig. 3. A pronounced characteristic of the microstructure is to form considerable amounts of LAGBs
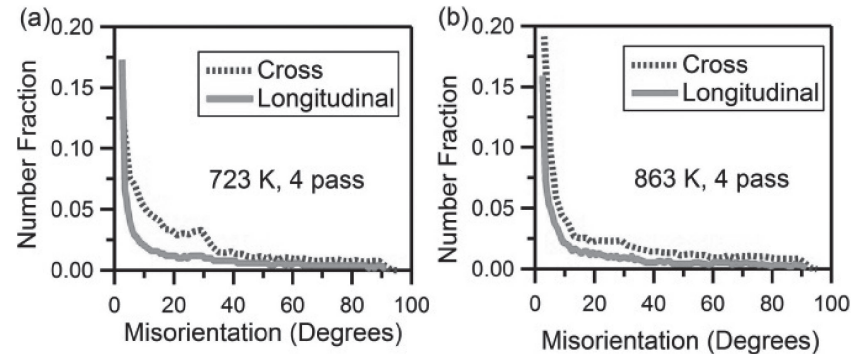

Fig. 3 Representative misorientation distributions after 4 passes at (a) $723 \mathrm{~K}$ and (b) $863 \mathrm{~K}$ on cross and longitudinal section, respectively.

(exhibited with white line, see Fig. 2). The primary driving force of DRV and DRX is provided by the energy stored in HAGBs and LAGBs. Within the interior of grains or subgrains, the magnitude of the energy stored in freely distributed dislocations (existed between HAGBs or LAGBs) is very small, and can be neglected. ${ }^{13)}$ So, only the energy stored within HAGBs and LAGBs, i.e., $\gamma_{\mathrm{s}}(\theta)$, is considered according to the Read-Shockley equation ${ }^{10,14)}$

$$
\gamma_{\mathrm{s}}(\theta)=\left\{\begin{array}{cc}
\gamma_{\mathrm{m}}\left(\frac{\theta}{\theta_{\mathrm{m}}}\right)\left(1-\ln \frac{\theta}{\theta_{\mathrm{m}}}\right) & \theta \leq \theta_{\mathrm{m}} \\
\gamma_{\mathrm{m}} & \theta>\theta_{\mathrm{m}}
\end{array}\right.
$$

where $\theta$ is grain boundary misorientation $\left(2\right.$ to $\left.100^{\circ}\right)$. The Read-Shockley equation describes the increase of stored energy with $\theta$, but the saturation of this increase occurs at $\theta_{\mathrm{m}}$ $\left(\sim 29^{\circ}\right)$, after which the stored energy keeps constant, i.e., $\gamma_{\mathrm{m}}$ $\left(\sim 0.6 \mathrm{~J} \mathrm{~m}^{-2}\right){ }^{15)}$ The mean value of $\gamma_{\mathrm{s}}(\theta)$ is given by $\bar{\gamma}_{\mathrm{s}}=$ $\sum_{\theta}\left[\gamma_{\mathrm{s}}(\theta) f(\theta)\right] / \sum_{\theta} f(\theta)$, where $f(\theta)$ is the number fraction of misorientation (Fig. 3). The average stored energy per unit volume $\left(E_{\mathrm{v}}\right)$ is given by $E_{\mathrm{v}}=\bar{\gamma}_{\mathrm{s}} S_{\mathrm{v}}$, where $S_{\mathrm{v}}(=2 / \bar{\ell}, \bar{\ell}$ : the average linear intercept between neighboring boundaries) is the area of grain boundary per unit volume. ${ }^{16)}$ The value of $\bar{\ell}$ was estimated by counting the number of whatever HAGBs or LAGBs along the orthogonal directions (Fig. 4). Consequently, one can arrive at $E_{\mathrm{v}}=2 \bar{\gamma}_{\mathrm{s}} / \bar{\ell}$ (Table 1).

The Read-Shockley equation was compared with the equation $E=\frac{1}{2} \rho G b^{2}$ (to estimate deformation energy), ${ }^{17)}$ where $b$ is the Burgers vector length $(=0.347 \mathrm{~nm}), G$ is the shear modulus $(=45.6 \mathrm{GPa})$, and $\rho$ is the dislocation density. For two reasons, the value of $\rho$, as estimated by averaging the ones of $\rho_{\mathrm{LAGB}}$ and $\rho_{\mathrm{HAGB}}$ (the dislocation densities due to LAGBs and HAGBs, respectively), is larger after ECAP at $723 \mathrm{~K}$ than that at $863 \mathrm{~K}$. First, $\rho_{\mathrm{LAGB}}$ is given by $\rho_{\mathrm{LAGB}}=$ $\left(\frac{3 \bar{\theta}_{\mathrm{LAGB}}}{b}\right) L^{-1},{ }^{18,19)}$ where $\bar{\theta}_{\mathrm{LAGB}}$ is an average misorientation across LAGBs, and $L$ is mean linear intercept between LAGBs. $\bar{\theta}_{\text {LAGB }}$ was greater, and $L$ was smaller at $723 \mathrm{~K}$ than that at $863 \mathrm{~K}$, respectively. Thus, $\rho_{\mathrm{LAGB}}$ is larger at $723 \mathrm{~K}$. Second, grain refinement was pronounced at $723 \mathrm{~K}$, at which $\rho_{\mathrm{HAGB}}$ was greater considering a larger area of grain boundary network (per unit volume) at finer grain sizes. Obviously, a region of greater value of $\rho$ (at HAGBs or LAGBs) deserves larger energy to be stored. $\rho$ is $\sim 10^{14} \mathrm{~m}^{-2}$ after plastic deformation. ${ }^{20)}$ Thus, $E=\frac{1}{2} \rho G b^{2}=0.27$ $\mathrm{MJ} \mathrm{m}^{-3}$ at $863 \mathrm{~K}$. By assuming a larger value of $\rho$ $\left(=0.5 \times 10^{15} \mathrm{~m}^{-2}\right)$ at $723 \mathrm{~K}$ (the reason for the increase of $\rho$ has been analyzed above), one arrives at $E=\frac{1}{2} \rho G b^{2}=$ $1.37 \mathrm{MJ} \mathrm{m}^{-3}$. Both values of $E$ are consistent with those of 

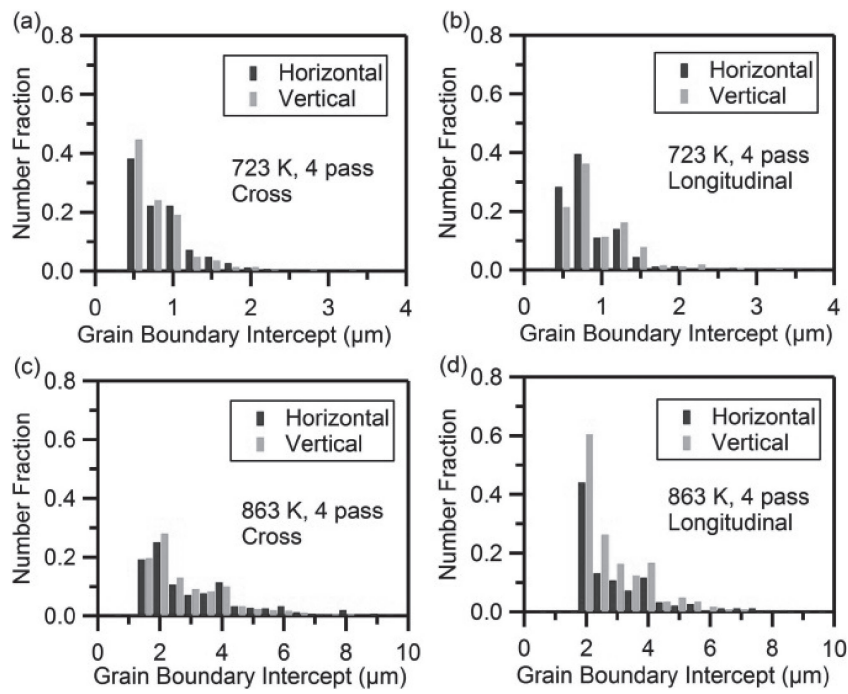

Fig. 4 Representative statistical histograms of the average linear intercept $(\bar{\ell})$ between neighboring boundaries (whether they are HAGBs or LAGBs): the recycling condition is for 4 passes at $723 \mathrm{~K}$ on (a) cross and (b) longitudinal section; at $863 \mathrm{~K}$ on (c) cross and (d) longitudinal section. The intercept was counted along orthogonal directions on each section of the sample.

$E_{\mathrm{v}}\left(E_{\mathrm{v}}\right.$ was measured by EBSD). Indeed, the stored energy is synonymous with deformation energy.

Hence, the formation of microstructure can be analyzed by estimating the value of the stored energy. Owing to a high stacking fault energy that titanium possesses, the climb or cross-slip of dislocations is prone to occur. ${ }^{7)}$ Thus, DRV is superior over DRX in titanium. Since the linear intercept between neighboring boundaries $(\bar{\ell})$ is wider after ECAP at $863 \mathrm{~K}$ than that at $723 \mathrm{~K}$, the stored energy $\left(E_{\mathrm{V}}\right)$ estimated at $863 \mathrm{~K}$ was smaller than that at $723 \mathrm{~K}$ (refer to the analysis above). As a result, the tendency of DRX was entirely prohibited at $863 \mathrm{~K}$ if the remnant stored energy was insufficient (There is always a competition between DRV and DRX. However, DRV would take priority in titanium. So, it was unlikely that DRX could be activated sufficiently at

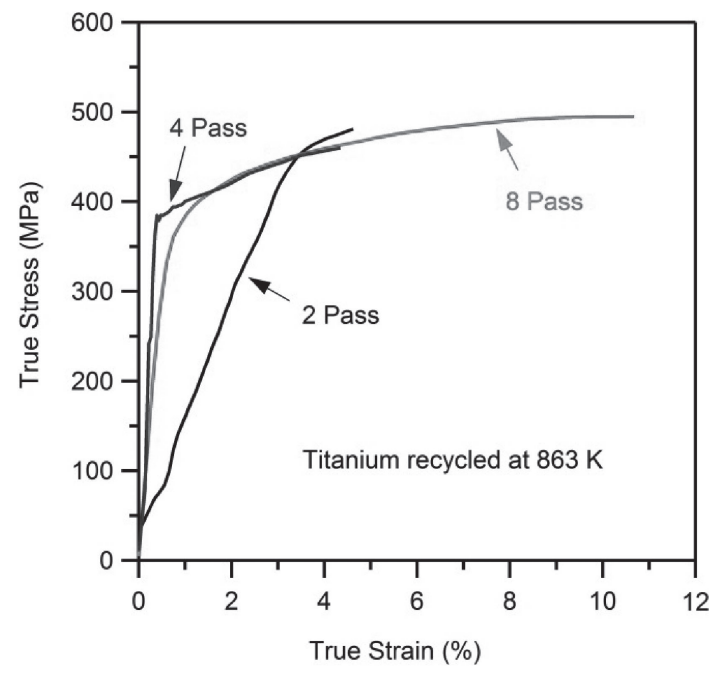

Fig. 5 Tensile curves of pure titanium recycled from chips by ECAP at $863 \mathrm{~K}$ for 2,4 and 8 passes, respectively.

the same time without enough stored energy). Because HAGBs could only be developed by DRX, the fraction of them $\left(f_{\mathrm{HAGB}}\right)$ at $863 \mathrm{~K}$ would be smaller than that at $723 \mathrm{~K}$. On the other hand, apart from DRV, significant DRX was driven by larger stored energy at $723 \mathrm{~K}$. Moreover, the thermal "agitation" by temperature was considerably alleviated at $723 \mathrm{~K}$. Therefore, a pronounced effect of the number of passes was imparted. As a result, HAGB fraction $\left(f_{\mathrm{HAGB}}\right)$ was consistently increased with the number of passes at $723 \mathrm{~K}$ (Table 1). This is consistent with the observation by Mishin et al. ${ }^{21)}$ reporting that larger misorientation across subdivided grains were formed with the extent of strains.

It is exceptionally meaningful to develop tensile ductility for the recycled titanium suffered from unfavorable oxide layers. As indicated by Fig. 5, the ductility of the chips recycled at $863 \mathrm{~K}$ was improved with the number of passes. No apparent ductility was achieved until the number of passes reached 4 (In this case, a uniform elongation $\sim 4 \%$ was observed). Essentially, two types of factors were considered

Table 1 Microstructure parameters and stored energy of commercial purity titanium recycled by ECAP at various temperatures ( $\left.T_{\mathrm{ECAP}}\right)$ and numbers of passes: average grain size $(d)$, the fraction of HAGBs $\left(f_{\mathrm{HAGB}}\right)$, mean linear intercept between LAGBs $(L)$, average misorientation across LAGB $\left(\bar{\theta}_{\mathrm{LAGB}}\right)$, the density of dislocations stored in LAGBs $\left(\rho_{\mathrm{LAGB}}\right)$, and the stored energy $\left(E_{\mathrm{v}}\right)$.

\begin{tabular}{|c|c|c|c|c|c|c|c|}
\hline$T_{\mathrm{ECAP}}(\mathrm{K})$ & Pass & $d(\mu \mathrm{m})$ & $f_{\mathrm{HAGB}}$ & $L(\mu \mathrm{m})$ & $\bar{\theta}_{\mathrm{LAGB}}\left(^{\circ}\right)$ & $\rho_{\mathrm{LAGB}}\left(\mathrm{m}^{-2}\right)$ & $E_{\mathrm{v}}\left(\mathrm{MJ} \mathrm{m}^{-3}\right)$ \\
\hline \multirow{3}{*}{723} & 2 & 1.1 & 0.4 & 1.45 & 6.1 & $6.34 \times 10^{14}$ & 0.96 \\
\hline & 4 & 1 & 0.54 & 1.8 & 6.3 & $5.28 \times 10^{14}$ & 1.23 \\
\hline & 8 & 1.15 & 0.56 & 2.3 & 5.8 & $3.8 \times 10^{14}$ & 1.02 \\
\hline \multirow{3}{*}{863} & 2 & 3.45 & 0.48 & 4.35 & 5.7 & $1.98 \times 10^{14}$ & 0.38 \\
\hline & 4 & 4.35 & 0.5 & 5.15 & 5.8 & $1.7 \times 10^{14}$ & 0.32 \\
\hline & 8 & 5.5 & 0.35 & 6.2 & 5.9 & $1.44 \times 10^{14}$ & 0.24 \\
\hline
\end{tabular}


to be responsible for satisfactory ductility, i.e., microstructure factor such as grain size and chemical composition, and metallurgical factor involving porosity/micro-crack and impurities (e.g., oxides). For microstructure factor, ultrafine grains was unfavourable to ductility because dislocations are less with the lack of coarse grains, and thus the ability to accommodate strain hardening was seriously impaired. Simultaneously, the enrichment of interstitials is negative to ductility because oxygen is detrimental by restricting twining and prismatic slip, and hydrogen may do in the same way by forming unfavourable hydrides. ${ }^{22,23)}$ In this study, as ECAP temperature was increased from 723 to $863 \mathrm{~K}$, the fluctuation of the content of oxygen was very limited (i.e., 0.19 to 0.22 mass $\%$ ), but the content of hydrogen was significantly enhanced from 0.003 to 0.014 mass $\%$. However, the ductility was much better at $863 \mathrm{~K}$ than that at $723 \mathrm{~K}$. This can be explained with the fact that the fracture behavior of Grade 2 commercial purity titanium is insensitive to hydrogen until its content exceeds 0.06 mass $\%{ }^{22}$ ) At the same time, it is rational to take high level of ECAP temperature $(863 \mathrm{~K})$ as a beneficial cause effective to eliminate unfavourable metallurgical factors (e.g., porosities and micro-cracks), and therefore, to strengthen the structure of bonding between chips.

Further, the ductility of the recycled titanium was understood by manifesting the failure mode of tensioned samples. The morphology of the fracture surface was revealed by SEM (see Fig. 6). As shown in Fig. 6(a), when the number of passes was 2 , even after recycling at $863 \mathrm{~K}$, delamination and micro-cracks were unavoidable due to the existence of oxide layers. This caused weak bonding strength and very limited ductility. An increase of the number of passes to 4 created a porosity-free fracture surface. Thus, compared with that obtained after 2 passes, more superior level of ductility $(\sim 4 \%)$ was achievable after 4 passes. Morphology of cleavage containing "tongues" and tear ridges (arrowed in Fig. 6(b)) was presented in the case of 4 passes. As shown in Fig. 6(c), vein-like profiles of the cleavage and some shallow ductile dimples were observed in the tensioned sample recycled for 8 passes. Obviously, the recycling for 8 passes endowed the sample excellent metallurgical quality thanks to the closure of voids and the absence of visible defects. In a word, high ECAP temperature $(863 \mathrm{~K})$ and sufficient numbers of passes (8) are responsible for excellent ductility with a uniform elongation up to $11 \%$.

\section{Conclusions}

Microstructure formation via DRV and DRX was considered to be driven by the stored energy in LAGBs and HAGBs, whose value after ECAP at $723 \mathrm{~K}$ is larger than that at $863 \mathrm{~K}$, by which more HAGBs were produced at $723 \mathrm{~K}$. The ductility of the recycled titanium was affected by a failure mode of cleavage. The analysis by EBSD and SEM fractography is useful to understand the microstructure and mechanical property of pure titanium recycled by SPD.

\section{Acknowledgements}

This study was supported by the Defence Materials
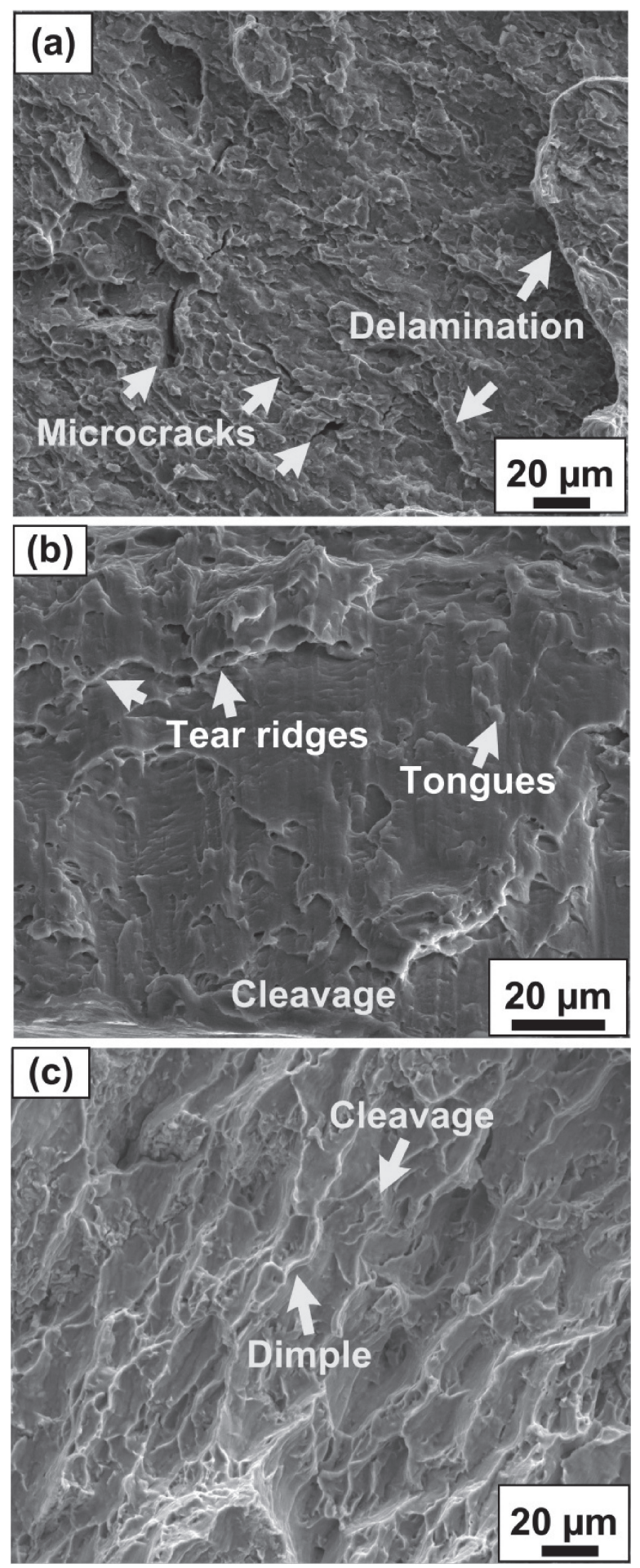

Fig. 6 SEM fractograph of the tensioned samples of pure titanium recycled at $863 \mathrm{~K}$ for (a) 2, (b) 4 and (c) 8 passes, respectively, exhibiting delamination and micro-cracks (for 2 passes), and the morphology of cleavage (tear ridges and tongues), as well as some shallow ductile dimples (after 4 or 8 passes).

Technology Centre. The author gratefully acknowledges the financial support from Shanghai Collaborative Innovation Centre for Heavy Casting/Forging Manufacturing Technology. My thanks are due to Q.D. Hu at Shanghai Jiaotong University, and K. Xia and D.T. McDonald with the University of Melbourne, for assistance with EBSD. This 
work was financially supported by the Practice Scheme via Industry-University-Research Cooperation for Shanghai Higher Education Teachers, as sponsored by Shanghai Municipal Education Commission.

\section{REFERENCES}

1) T. Aizawa, K. Halada and T.G. Gutowski: Mater. Trans. 43 (2002) 390396.

2) A.P. Zhilyaev, A.A. Gimazov, G.I. Raab and T.G. Langdon: Mater. Sci. Eng. A 486 (2008) 123-126.

3) M.I. Abd El Aal, E.Y. Yoon and H.S. Kim: Mater. Sci. Eng. A 560 (2013) 121-128.

4) Y. Nakada: Philos. Mag. 11 (1965) 251-261.

5) A. Godfrey and Q. Liu: Scr. Mater. 60 (2009) 1050-1055.

6) F.J. Humphreys: J. Mater. Sci. 36 (2001) 3833-3854.

7) P. Luo, D.T. McDonald, W. Xu, S. Palanisamy, M.S. Dargusch and K. Xia: Scr. Mater. 66 (2012) 785-788.

8) P. Luo, Q.D. Hu and X. Wu: Metall. Mater. Trans. A 47 (2016) 1922 1928.

9) Q.D. Hu, P. Luo, Y.W. Yan and J.G. Li: Metall. Mater. Trans. A 46 (2015) 1443-1449.

10) F.J. Humphreys and M. Hatherly: Recrystallization and Related Annealing Phenomena, 2nd ed., (Elsevier, Oxford, 2004).
11) K. Oh-Ishi, Z. Horita, M. Furukawa, M. Nemoto and T.G. Langdon: Metall. Mater. Trans. A 29 (1998) 2011-2013.

12) P. Luo and Q.D. Hu: Metall. Mater. Trans. A 44 (2013) 1651-1655.

13) A. Godfrey, W.Q. Cao, N. Hansen and Q. Liu: Metall. Mater. Trans. A 36 (2005) 2371-2378.

14) W.Q. Cao, A. Godfrey, N. Hansen and Q. Liu: Metall. Mater. Trans. A 40 (2009) 204-214.

15) W.T. Read: Dislocations in Crystals, (McGraw-Hill, New York, 1953).

16) M.A. Meyers and K.K. Chawla: Mechanical Behavior of Materials, 2nd ed., (Cambridge University Press, Cambridge, 2009).

17) G. Gottstein, D.A. Molodov and L.S. Shvindlerman: Grain-boundary energy and mobility, in Metal Process Simulation, ASM Handbook, vol. 22B, ed. by D.U. Furrer and S.L. Semiatin, (ASM International, Materials Park, OH, 2010) p. 67.

18) W.C. Liu, P.P. Zhai and C.-S. Man: Mater. Sci. Eng. A 531 (2012) 178181.

19) N. Hansen and X. Huang: Acta Mater. 46 (1998) 1827-1836.

20) R.W.K. Honeycombe: The Plastic Deformation of Metals, (Edward Arnold, London, 1968).

21) O.V. Mishin, D. Juul Jensen and N. Hansen: Mater. Sci. Eng. A 342 (2003) 320-328.

22) M.L. Wasz, F.R. Brotzen, R.B. Mclellan and A.J. Griffin, Jr.: Int. Mater. Rev. 41 (1996) 1-12.

23) E. Baril, L.P. Lefebvre and Y. Thomas: Powder Metall. 54 (2011) 183186. 